\title{
Reativações pós-silurianas do Lineamento Transbrasiliano na porção sul da Bacia do Parnaíba
}

\author{
Post-silurian reactivations of the Transbrasiliano
}

Lineament in the southern portion of the Parnaiba Basin

\author{
Carla Hemillay de Oliveira Santos ${ }^{1}$, Emanuel Ferraz Jardim de Sá1,2, \\ Fernando César Alves da Silva ${ }^{1,2}$, Alex Francisco Antunes ${ }^{2}$ \\ 1Programa de Pós-Graduação em Geodinâmica e Geofísica, Universidade Federal do Rio Grande do Norte - UFRN, \\ Campus Universitário, Lagoa Nova, Caixa Postal 1596, CEP 59078-970, Natal, RN, BR (carlahemillay@hotmail.com) \\ 2Departamento de Geologia, Universidade Federal do Rio Grande do Norte - UFRN, Natal, RN, BR (emanuel@ccet.ufrn.br; \\ fernando@geologia.ufrn.br; alex@ccet.ufrn.br)
}

Recebido em 24 de julho de 2017; aceito em 20 de abril de 2018

\begin{abstract}
Resumo
O Lineamento Transbrasiliano (LTB) apresenta direção NE-SW. Cerca de $900 \mathrm{~km}$ desse sistema interceptam o substrato da Bacia do Parnaíba (BPar), inferido, a partir de dados geológicos e geofísicos, como uma zona de cisalhamento plástica transcorrente dextral. Este trabalho objetivou abordar a assinatura estrutural e os marcadores estratigráficos associados às reativações do LTB na região sul da bacia, ao leste de Palmas (TO). No embasamento cristalino, um estágio tardio do LTB se expressa como uma zona dúctil-frágil também de cinemática dextral de idade ediacarana-cambriana, no NW do Ceará. Nas unidades litoestratigráficas da BPar são distinguidos eventos de reativação em regime frágil ou hidroplástico. Na região de estudo, um evento mais antigo registra cinemática transcorrente sinistral expressa principalmente como bandas de deformação e falhas com direção NE, combinadas a estruturas dilatacionais (incluindo juntas e falhas normais) ou conjugadas/antitéticas de rejeito direcional ou oblíquo, com orientações que variam de NNE a NNW, todas observadas nos litotipos das Formações Sambaíba e Pedra de Fogo, bem como nas mais antigas. Ao sudeste de Alto Parnaíba (MA) são observadas evidências de atividade tectônica sindeposicional durante o Permiano superior. Um segundo conjunto de estruturas é composto por falhas normais associadas a uma distensão N/NNW, impressas nos corpos básicos de idade eojurássica da Suíte Mosquito, que, por sua vez, é capeada por depósitos com seixos das vulcânicas, correlacionados à Formação Corda. Um terceiro conjunto de estruturas, caracterizado por falhas normais ou oblíquas com direção NE, registra distensão NW, sendo associada ao evento de rifteamento da Margem Leste brasileira, durante o Cretáceo Inferior. Finalmente, um quarto evento, de ocorrência restrita, envolve distensão NE e está registrado em arenitos correlacionados ao Grupo Urucuia, implicando uma idade máxima neocretácea.
\end{abstract}

Palavras-chave: Bacia do Parnaíba; Lineamento Transbrasiliano; Evolução estrutural.

\begin{abstract}
The Transbrasiliano lineament trends NE-SW, and about $900 \mathrm{~km}$ of it occurs in the substrate of the Parnaíba Basin, inferred to be a plastic shear zone with dextral strike-slip kinematics based on geological and geophysical data. This paper addresses the structural signature and age of Transbrasiliano lineament reactivations in the southern region of the basin, east of the city of Palmas. In the crystalline basement, a late, ductile-brittle stage of Transbrasiliano lineament also displays dextral kinematics of ediacara-cambrian age, as observed in NW Ceará State. In the lithostratigraphic units of the Parnaíba Basin, reactivation events under brittle or hydroplastic conditions are recognized. In the studied region, an older event of sinistral transcurrent kinematics is expressed by NE-trending deformation bands and faults, combined with oblique structures, either dilatational (including joints and normal faults) or conjugate/antithetic strike-slip or oblique-slip structures. Their orientation ranges from NNE to NNW, as observed in the Sambaíba, Pedra de Fogo and older formations. In the southeast of Alto Parnaíba, evidence of neopermian, syndepositional tectonic activity was observed. A second set of structures is extensional joints or oblique-slip and normal faults associated to a N/NNW extension, overprinted in the eojurassic basic rocks of the Mosquito Suite. Sandstones bearing volcanic clasts were correlated to the Corda Formation and overly basic sills. A third set of structures, characterized by NE-trending normal or oblique faults, reflects a NW extension, as it is correlated to the rifting event in the Brazilian Eastern Margin during the Eocretaceous. Finally, a fourth event, with a more restrict occurrence, involves NE extension, as it is also observed in the Urucuia Group sandstones, implying a Neocretaceous age for this event.
\end{abstract}

Keywords: Parnaíba Basin; Transbrasiliano Lineament; Structural evolution. 


\section{INTRODUÇÃO}

O Lineamento Transbrasiliano (LTB) foi definido por Schobbenhaus (1975) como uma faixa cataclasada, de direção NE-SW, com cerca de $2.700 \mathrm{~km}$ de extensão no território brasileiro. O LTB intercepta terrenos entre os Crátons Amazônico e São Francisco, adentrando o Paraguai e a Argentina, tendo também continuidade no continente africano (Attoh e Brown, 2008). Sua origem e evolução são amplamente discutidas por diversos autores (Almeida e Carneiro, 2004; Cordani et al., 2013; Castro et al., 2014, 2016; Amaral et al., 2017), sendo geralmente atribuídas ao desenvolvimento de zonas de cisalhamento transcorrentes dextrais durante o estágio tardi a pós-colisional da Orogênese Brasiliana, entre o Neoproterozoico e o Cambriano. Ganade de Araújo et al. (2014) sugerem que essa estrutura dúctil representaria o registro de uma megassutura associada à formação do Supercontinente Gondwana.

Cerca de $900 \mathrm{~km}$ dessa importante descontinuidade ocorrem no perímetro da Bacia do Parnaíba (BPar), sendo inferidos no seu substrato controlando estruturas de grábens preenchidos por depósitos pré-silurianos (Castro et al., 2014, 2016; Morais Neto, 2013; Antunes et al., 2015). Diversos eventos de reativação frágil são reconhecidos no Fanerozoico ao longo do traço do LTB, afetando ou condicionando unidades sedimentares e vulcânicas da BPar (Chamani, 2011, 2015; Cacama et al., 2015; Lima, 2015). Todavia, a geometria das estruturas, a cinemática e a idade dos eventos deformacionais pós-ordovicianos, ao longo do LTB, ainda são pouco conhecidas, especialmente na porção sul da bacia.

O presente trabalho objetivou abordar a assinatura estrutural das reativações fanerozoicas do LTB na sua porção sul (leste de Palmas, TO) da BPar. Na área de estudo ocorrem o embasamento Pré-Cambriano, que expõe a continuidade aflorante da zona milonítica do LTB, três sequências deposicionais de idade paleozoica a triássica, rochas magmáticas da Suíte Mosquito e unidades sedimentares cretáceas, pertencentes à Bacia do Espigão-Mestre (porção norte da Bacia Sanfranciscana). Observa-se que, nessa região, a cartografia disponível (Vasconcelos et al., 2004) interpreta movimento direcional dextral ao longo do LTB, inclusive afetando as unidades neocretáceas do Grupo Urucuia (Figura 1).

\section{CONTEXTUALIZAÇÃO GEOLÓGICA REGIONAL}

\section{O embasamento cristalino Pré-Cambriano e a Bacia do Parnaíba}

A BPar é parte do grupo de grandes sinéclises paleozoicas brasileiras, com as Bacias do Paraná, Solimões e Amazonas. Encontra-se localizada no Norte-Nordeste brasileiro, ocupando uma área de cerca de $600.000 \mathrm{~km}^{2}$ que engloba parte dos Estados do Piauí, do Maranhão, do Tocantins, do Pará, do Ceará e da Bahia (Góes e Feijó, 1994).

O embasamento Pré-Cambriano da BPar, fortemente estruturado, é composto por rochas formadas ou retrabalhadas no ciclo orogênico Brasiliano, que fazem parte das faixas Araguaia, Brasília (extremo norte), Rio Preto e outras da Província Borborema, as quais circundam os Crátons Amazônico e São Francisco. Reativações da trama estrutural do embasamento são particularmente expressivas nos limites sudeste e oeste da bacia, respectivamente. O limite norte da BPar é marcado pelas bacias da Margem Equatorial, pela Faixa Gurupi e pelo Cráton São Luís (Figura 1).

Diferentes autores propõem que o substrato da BPar se encontra estruturado por uma série de grábens correlacionáveis à Bacia de Jaibaras, no NW do Ceará, e outros exemplos de bacias tardias ao evento orogênico Brasiliano (Nunes, 1993; Cordani et al., 2009; Castro et al., 2014, 2016; Morais Neto, 2013; Antunes et al., 2015). Esses grábens poderiam representar uma fase inicial de subsidência mecânica, seguida pela implantação da sinéclise marcando o estágio de subsidência termal (Oliveira e Mohriak, 2003). Essas estruturas estão preenchidas por depósitos pré-silurianos. Altos estruturais e eixos deposicionais de unidades paleozoicas também são relacionados ao controle do LTB no substrato da BPar (Cordani et al., 2013). Conforme descrito por Jardim de Sá et al. (2015) e Cacama et al. (2015), a expressão do LTB no interior da BPar corresponde a falhas e juntas nas unidades pós-ordovicianas, com diferentes idades e associadas à atuação de novos campos de tensões, ainda no contexto paleotectônico do Gondwana ou relacionadas à formação das Margens Leste e Equatorial sul-americanas. Essas sucessivas reativações também foram documentadas por Chamani $(2011,2015)$, sob a forma de estruturas sindeposicionais originadas por eventos sísmicos.

Em termos de registro estratigráfico (Vaz et al., 2007), a bacia apresenta uma sucessão de rochas sedimentares, além de suítes magmáticas, englobadas em quatro sequências deposicionais (Figura 1). As unidades mais antigas incluem as sequências Siluriana (representada pelas rochas siliciclásticas de sistemas fluviais e pelitos plataformais do Grupo Serra Grande), Mesodevoniana-Eocarbonífera (representada pelas rochas siliciclásticas de sistemas plataformais e deltaicos do Grupo Canindé) e Neocarbonífera-Eotriássica (representada por depósitos clástico-evaporíticos do Grupo Balsas).

A partir do Jurássico Inferior, mudanças significativas ocorreram na bacia, incluindo derrames basálticos e intrusões de soleiras de diabásio da Suíte Mosquito (Figura 1). Esse evento é correlacionado à abertura do Oceano Atlântico Central, sendo proposto que a carga exercida pelas rochas ígneas teria gerado espaço para a deposição da Formação Pastos Bons, que compõe a Sequência Jurássica (Góes, 1995; Vaz et al., 2007). Durante o Cretáceo Inferior, com o início dos processos de formação do Oceano Atlântico Sul, ocorreu um novo 
evento magmático básico (Suíte Sardinha) e a deposição da Sequência Cretácea, formada por depósitos continentais e, a partir do Aptiano, por sucessões marinhas e costeiras, estas ocorrendo na porção centro-norte da bacia (Vaz et al., 2007).

\section{Geologia da região sul da Bacia do Parnaíba}

A área de estudo localiza-se entre os meridianos de Palmas (TO) e Gilbués (PI), e exibe rochas do embasamento cristalino que, em imagens orbitais da sua porção SW, ressaltam o padrão sigmoidal dextral do LTB. Essa estrutura é capeada por rochas sedimentares dos Grupos Serra Grande, Canindé e Balsas (destaca-se a ausência da Formação Motuca na área estudada), havendo ainda a ocorrência de corpos magmáticos pertencentes à Suíte Mosquito, ao sul da cidade de Lizarda
(TO). Os mapas preexistentes (Folha SC.23/Curimatá Arcanjo e Braz Filho, 1999; Folha SC.23/Rio São Francisco Vasconcelos et al., 2004) na região não identificam áreas aflorantes das Formações Corda e Pastos Bons, pertencentes à Sequência Jurássica da BPar. Em adição, a área de estudo engloba a borda norte da Bacia do Espigão Mestre (Grupos Urucuia e Areado, que integram a Sequência Cretácea), que pode registrar as reativações (dextrais, naqueles mapas) mais jovens do LTB. São observados lineamentos com direção NE-SW (que correspondem a feixes do LTB na bacia), N-S e E-W (ENE, ver Figura 2), estes últimos, pelo menos em parte, associados às ocorrências da Suíte Mosquito.

A área de estudo e o LTB também foram objeto de pesquisa de outros autores, a exemplo de Chamani (2011, 2015). O autor descreve que zonas de fraqueza litosféricas

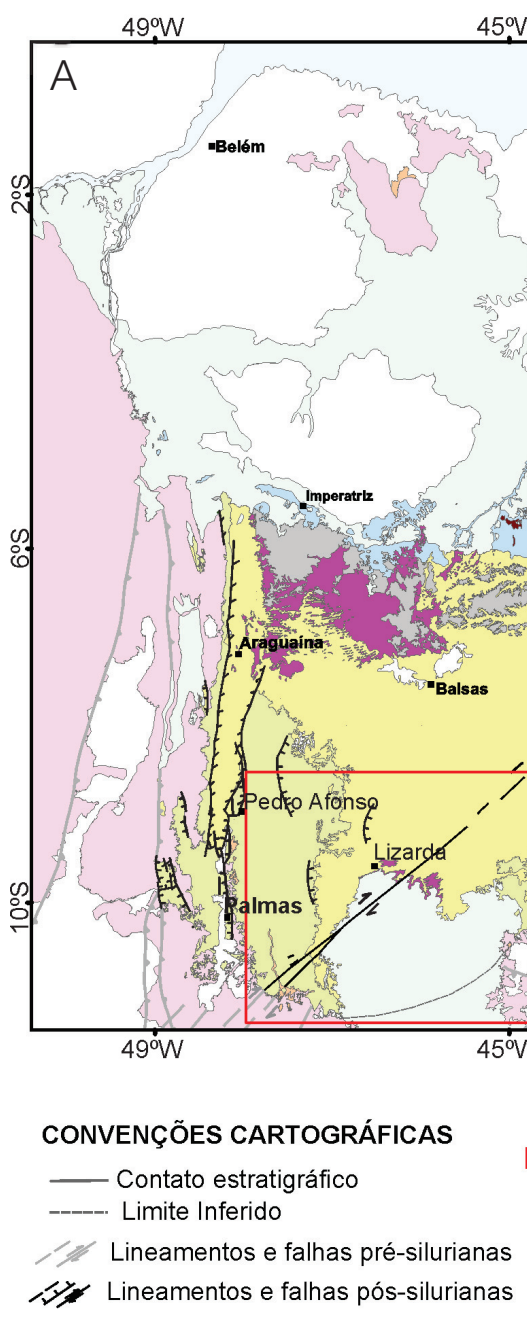

$45 \% \mathrm{~W}$
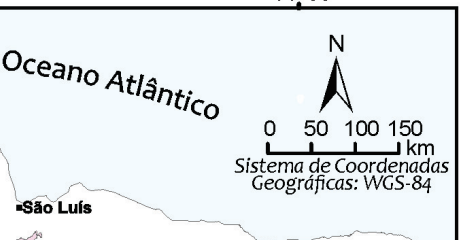
410

\section{SEQUÊNCIAS DEPOSICIONAIS \\ Paleógeno a Neógeno}

Coberturas recentes

Eo a Neocretáceo/Aptiano - Cenomaniano

Sequência Neoalbiana - Cenomaniana

Sequência Aptiana - Eoalbiana

Eocretáceo/Barremiano

Suíte Magmática Sardinha

Jurássico

$\square$ Sequência Jurássica

Suíte Magmática Mosquito

\% Neocarbonífero - Eotriássico

of Sequência Neocarbonífera - Eotriássica

Mesodevoniano - Eocarbonífero

Sequência Mesodevoniana - Eocarbonífera Siluriano

CD $\downarrow \square$ Sequência Siluriana

Ediacarano - Cambriano

$\square$ Grupo Jaibaras

Criogeniano - Ediacarano

Grupo Ubajara

Pré-Cambriano - Cambriano

\section{$\square$ Terrenos pré-cambrianos a cambrianos \\ Picosing}

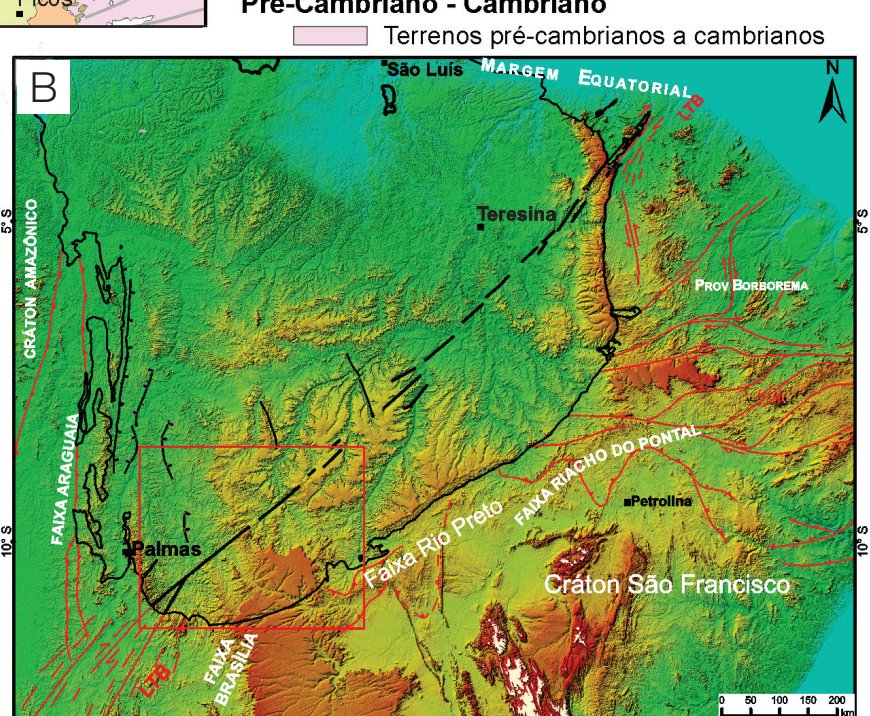

Figura 1. (A) Mapa geológico (compilado de Schobbenhaus et al., 2004, com modificações do Projeto Bacia do Parnaíba). (B) Modelo Digital do Terreno da BPar e domínios adjacentes. Foram assinaladas algumas das estruturas principais, em especial as falhas (em preto, na bacia) e zonas de cisalhamento (traços e foliações no substrato Pré-Cambriano, em vermelho) ao longo do trend do Lineamento Transbrasiliano. 

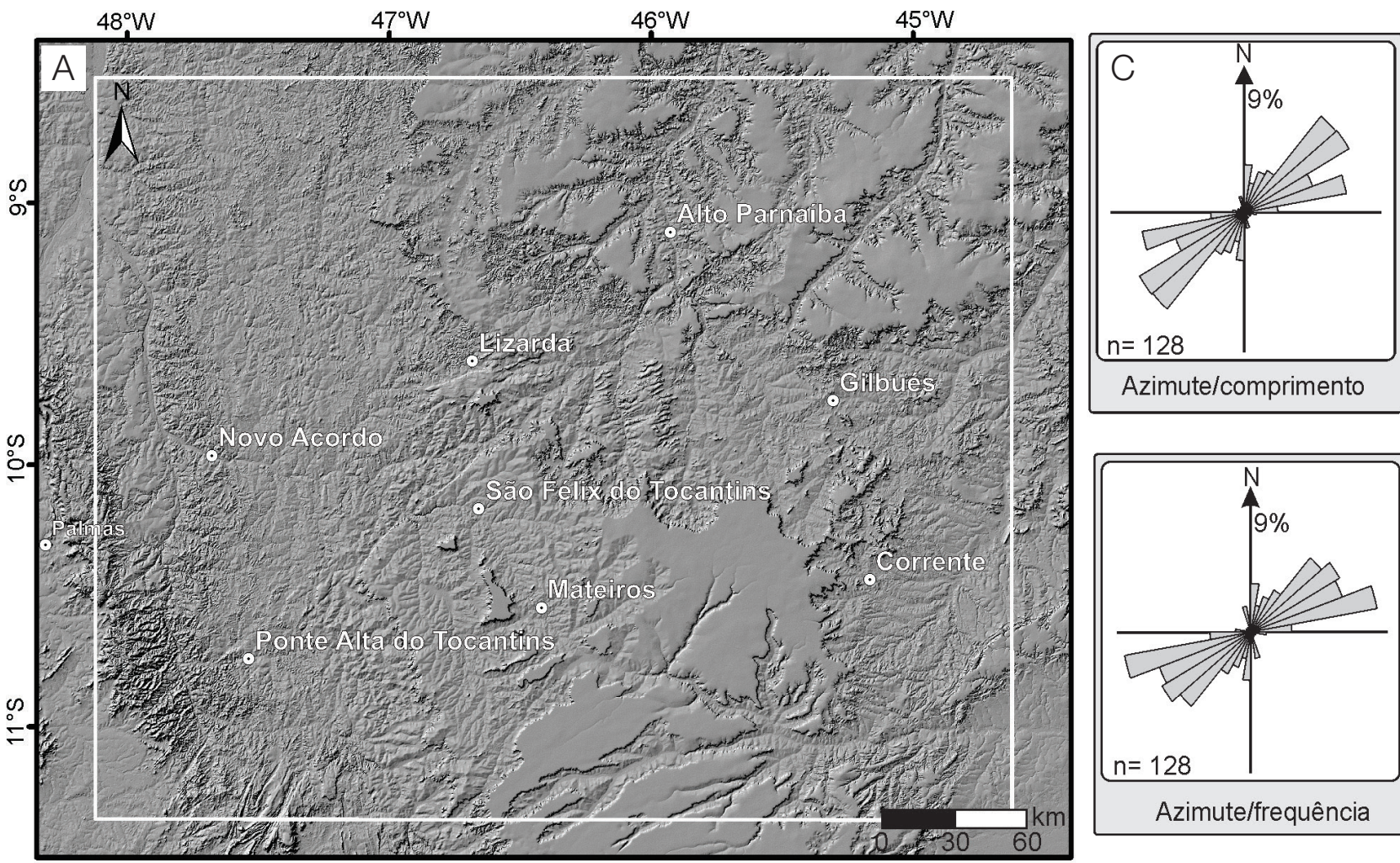

Azimute/comprimento

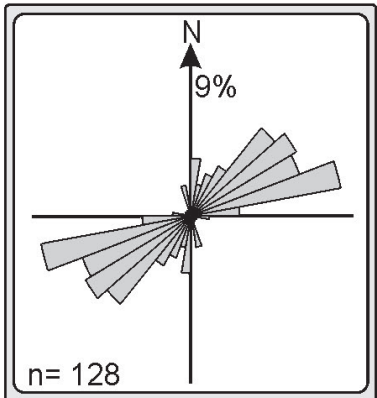

Azimute/frequência

Lineamentos inferidos na cobertura cretácea

Lineamentos, que em parte, afetam/controlam os corpos magmáticos eojurássicos e unidades mais antigas

1 Lineamentos em parte compatíveis com reativações do LTB

$/$ Traço principal

Contorno da BPar

$/$ Lineamentos do

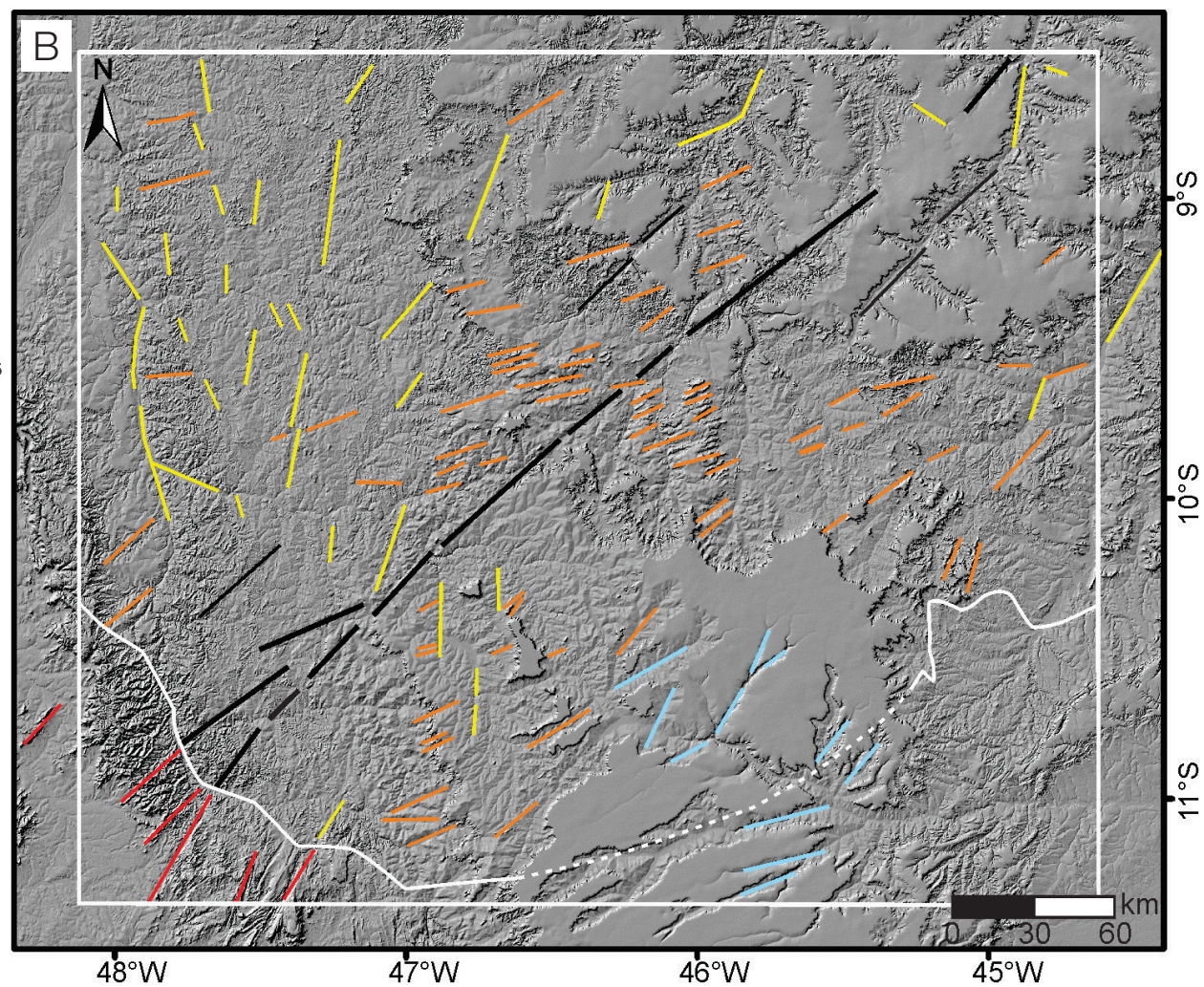

Figura 2. (A) Imagem SRTM com iluminação de $310^{\circ}$. (B) Imagem SRTM com traços de fotolineamentos e fotolineações. (C) Diagramas de rosetas de azimute/comprimento e azimute/frequências. O retângulo branco representa o limite da área de estudo. 
importantes, como o LTB, tendem a concentrar esforços remotos gerados nas bordas das placas e, dessa forma, ser foco de atividade tectônica e sismicidade intraplaca. $\mathrm{O}$ autor aplicou uma metodologia para identificar o agente desencadeador da deformação sindeposicional, permitindo a distinção entre agentes de deformação autógenos e agentes de deformação alógenos, e, entre estes, identificar estruturas produzidas por abalos sísmicos. A partir de sua caracterização como possíveis sismitos, as estruturas são interpretadas como indicadores cronológicos de atividade tectônica sindeposicional. O autor concluiu que o "Sistema de Falhas Transbrasiliano" (por ele assim denominado) sofreu repetidas fases de atividade sismotectônica, todavia sem identificar com mais rigor a assinatura cinemática desses eventos.

\section{MÉTODOS DE TRABALHO}

Para a obtenção dos dados requeridos para este trabalho foi aplicada a seguinte sistemática:

1. análise preliminar das folhas 1:250.000 (Folha SC.23/ Curimatá - Arcanjo e Braz Filho, 1999) e 1:1.000.000 (Folha SC.23/Rio São Francisco - Vasconcelos et al., 2004), disponíveis no banco de dados da Companhia de Pesquisa de Recursos Minerais - CPRM;

2. análise preliminar de fotolineamentos e macroestruturas, em imagens digitais SRTM; também foi feito uso do aplicativo Google Earth para seleção de afloramentos e rotas de acesso para o trabalho de campo;

3. etapa de trabalho de campo envolvendo a aquisição de dados litológicos, estratigráficos e estruturais;

4. os dados de campo foram analisados (análise geométrica e cinemática em diagramas estereográficos) e comparados com os lineamentos interpretados nas imagens, buscando identificar sua cronologia (em comparação com marcadores cronoestratigráficos) e cinemática;

5. interpretação de uma linha sísmica (0240-0316), com mapeamento das principais estruturas e correlação com os lineamentos nas imagens e mapas geológicos. $\mathrm{O}$ trabalho enfatizou a caracterização de reativações ao longo do LTB.

O Projeto Bacia do Parnaíba (contrato Chevron Brasil/ Universidade Federal do Rio Grande do Norte - UFRN/ Programa de Pós-Graduação em Geodinâmica e Geofísica PPGG) forneceu os dados citados e custeou o trabalho de campo.

\section{Análise de lineamentos em produtos de sensores remotos}

As imagens digitais SRTM, com resolução espacial de $90 \mathrm{~m}$ (adquiridas no sítio do USGS e com referencial planialtimétrico WGS84) foram utilizadas para a cartografia de fotolineamentos (aqui entendidos como traços em superfície de estruturas descontínuas, falhas e fraturas) na porção sul da BPar com ênfase no LTB, bem como fotolineações (traços de estruturas contínuas, compondo o fabric do embasamento). Com a finalidade de ressaltar o principal trend do LTB (NE-SW), utilizou-se uma iluminação proveniente de NW, gerando relevo sombreado que realça as estruturas NE-SW.

A construção de diagramas de rosetas foi realizada no software RockWorks 16 e baseou-se no método de contagem de azimute por comprimento e frequência dos fotolineamentos.

\section{Revisão da cartografia geológica}

Os trabalhos de campo permitiram a coleta de dados litoestratigráficos que implicavam em efetuar modificações na cartografia da CPRM, em especial buscando delimitar as áreas aflorantes das unidades cretáceas da Bacia Sanfranciscana. Além dos dados de afloramentos e considerando os mergulhos sub-horizontais amplamente dominantes na região, a revisão cartográfica foi baseada nas variações de cotas topográficas das unidades litoestratigráficas de interesse. Essas cotas foram adquiridas com o auxílio da ferramenta Raster Surface Contour, visualizada no programa ArcGis.10.1. Foi possível extrair as curvas de níveis adequadas para delimitar base/ topo das unidades em estudo, a partir da comparação entre o modelo digital de elevação do terreno, a base geológica da CPRM e os novos dados de campo. A partir dessa comparação, foram selecionadas as curvas que melhor refletem a área aflorante dos Grupos Areado e Urucuia, e de algumas unidades sotopostas da BPar (Formações Pedra de Fogo e Sambaíba).

\section{Análise de macroestruturas em subsuperfície}

A interpretação de uma linha sísmica (0240-0316) na porção sul da BPar, com direção ENE, aliada à correlação com dados de superfície (imagens SRTM e dados de campo), permitiu uma melhor caracterização do arcabouço estrutural da região. Na ausência de poços na região, foram interpretados alguns horizontes que, pela semelhança nas sismofácies (em relação às malhas sísmicas e aos dados de poços, mais ao norte na bacia), correspondem aos topos de algumas das principais unidades. Em seguida, realizou-se a interpretação estrutural qualitativa de falhas, identificando componentes de mergulho e sua geometria de alto ângulo, concentradas na região que corresponde ao traço do LTB em superfície.

\section{Análise de mesoestruturas}

Os dados coletados em campo incluem principalmente medidas de falhas e bandas de deformação (e, com menor frequência, juntas), sempre que possível amostrando planos, slickenlines e indicadores cinemáticos associados (além do contexto tectônico e dos marcadores cronoestratigráficos envolvidos). Os conjuntos de dados foram discriminados em populações 
com estilo e cinemática coerentes entre si. Essa análise envolveu o tratamento dos dados estruturais, plotados em projeções equi-área (Schmidt-Lambert, hemisfério inferior) no software Faultkin, de modo a suportar a discriminação preliminar a partir da orientação dessas estruturas e dos fotolineamentos no entorno dos afloramentos. Por fim, a cronologia das estruturas foi estabelecida com base nas unidades sedimentares afetadas, na correlação com rochas básicas e em eventos geodinâmicos reconhecidos no entorno da BPar, seguindo proposta de Jardim de Sá et al. (2015). As estruturas caracterizadas foram ainda comparadas entre si com base em modelos de cisalhamento e no sistema de fraturas de Riedel, com especial atenção às etapas de reativações do LTB e às estruturas análogas também com orientação NE-SW.

\section{RESULTADOS}

\section{Análise e interpretação de lineamentos}

A análise das imagens e a confecção de diagramas de roseta permitiram identificar três famílias de lineamentos - NE-SW, $\mathrm{N}-\mathrm{S}$ (NNE a NNW) e ENE-WNW -, os quais possuem comprimentos que variam entre 3 a $80 \mathrm{~km}$ (Figura 2). Os lineamentos com maior comprimento apresentam direção NE-SW, característica do LTB, e sua expressão é marcante nas cenas do Google Earth na região do Jalapão (exemplo na Figura 3). Já os lineamentos mais frequentes, na área de estudo, são os de azimute ENE-WNW, todavia em parte se confundindo (via orientações intermediárias) com aqueles de azimute NE-SW. Em sua maioria, a geometria retilínea desses lineamentos conduz a interpretá-los como traços de fraturas subverticais, sejam falhas de rejeito direcional ou normais, sejam megajuntas de distensão.

Os lineamentos de direção NE-SW, mais expressivos (traços pretos na Figura 2), estão presentes predominantemente na região central da área de estudo, entre as cidades de Alto Parnaíba (MA) e Ponte Alta do Tocantins (TO), compondo o traço do LTB (Figura 2). Verifica-se a sua correspondência, em campo, com estruturas de cinemática distensional ou transcorrente (ver adiante). Tais lineamentos afetam unidades desde a Sequência Siluriana até a Sequência Neocarbonífera-Eotriássica, bem como o embasamento cristalino, nele coincidindo com o trend NE da zona de cisalhamento brasiliana (incluindo a sua expressão tardia de baixa temperatura, ou como reativações posteriores).

Lineamentos com azimute NE-SW (traços azuis na Figura 2) também foram identificados nos platôs mais elevados da região (sustentados pelo Grupo Urucuia). Dado o restrito controle de campo (os afloramentos visitados ao sul da cidade de Lizarda (TO) exibem principalmente mesofalhas com direção NW e componente de rejeito normal ou normal oblíquo), presume-se que esses lineamentos, seguindo vales incisos nos platôs, sejam feições passivas controladas por estruturas NE impressas nas unidades mais antigas, subjacentes.

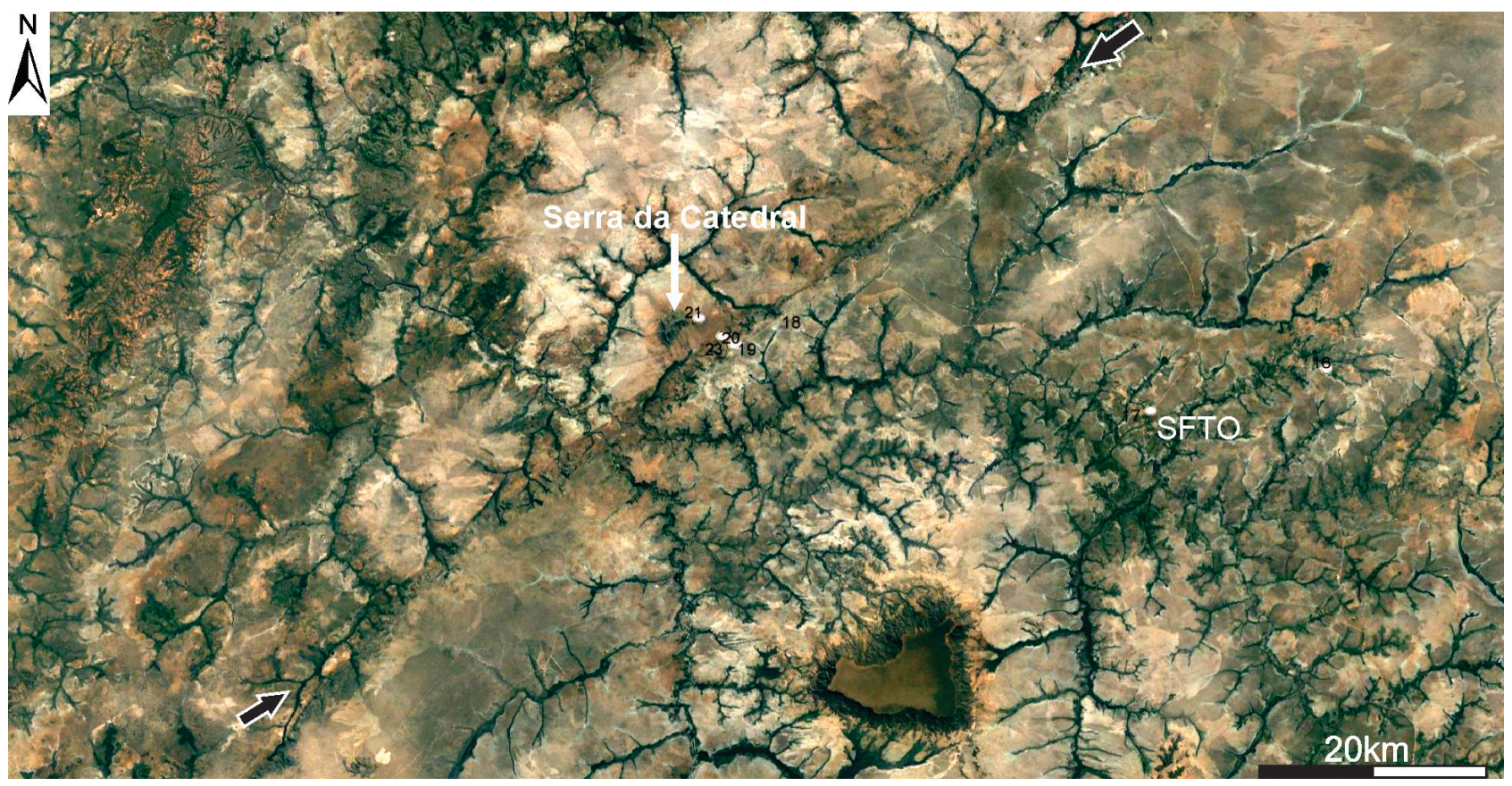

Figura 3. Imagem do Google Earth da região do Jalapão, destacando o trend NE-SW de um segmento do Lineamento Transbrasiliano (setas pretas) e a localização da Serra da Catedral, importante monumento natural da região. SFTO corresponde à sede municipal de São Félix do Tocantins; o platô a SW é sustentado pelos arenitos do Grupo Urucuia. Localização dessa visada está na Figura 4. 
Os fotolineamentos de direção em torno de N-S (traços amarelos na Figura 2) apresentam comprimentos que chegam a cerca de $40 \mathrm{~km}$ (Figura 2). Embora de ocorrência mais restrita, eles são os mais frequentes ao NW do traço principal do LTB (região de Novo Acordo, TO) e também no entorno de Mateiros (TO). Sua correspondência em campo é feita com juntas de distensão ou falhas normais ou normais oblíquas que seccionam as rochas das unidades paleozoicas. Também deve-se mencionar a importância desses fotolineamentos na borda oeste da bacia, delimitando o Gráben de Araguaína (Souza, 2016).

A estruturação de direção ENE-WSW (traços laranjas na Figura 2) é muito expressiva nas proximidades da cidade de Lizarda (TO), bem como ao sul e ao leste/NE desta (Figura 2), com comprimentos individuais variando de 5 a $60 \mathrm{~km}$, sendo os mais frequentes na região. Nessa figura, observa-se que os lineamentos ENE (que afetam ou controlam os corpos básicos da Suíte Mosquito na região de Lizarda) aparentam não ter continuidade nos platôs ocupados por unidades cretáceas, mais ao sul. Em campo, esses lineamentos associam-se com falhas de regime normais ou juntas de distensão. Ainda na Figura 2 observa-se a sua ocorrência também em áreas ocupadas pela Formação Sambaíba e pelas unidades mais antigas da Sequência Neocarbonífera a Neotriássica.

\section{Revisão da cartografia geológica e suas implicações}

Os dados de campo constataram algumas imprecisões na cartografia geológica (incluindo correlações estratigráficas), que apresentam implicações para a calibração cronológica dos eventos deformacionais reconhecidos. Os mapas preexistentes (Vasconcelos et al., 2004) ilustram o feixe principal do LTB interceptando as unidades neocretáceas do Grupo Urucuia (Bacia do Espigão Mestre, expressão norte da Bacia Sanfranciscana), assim induzindo a interpretação de uma reativação do LTB nessa idade, com uma movimentação direcional dextral (ver Figura 1).

Os mapas altimétricos e os dados de campo (Figura 4A) permitiram avaliar que os litotipos do Grupo Urucuia ocupam

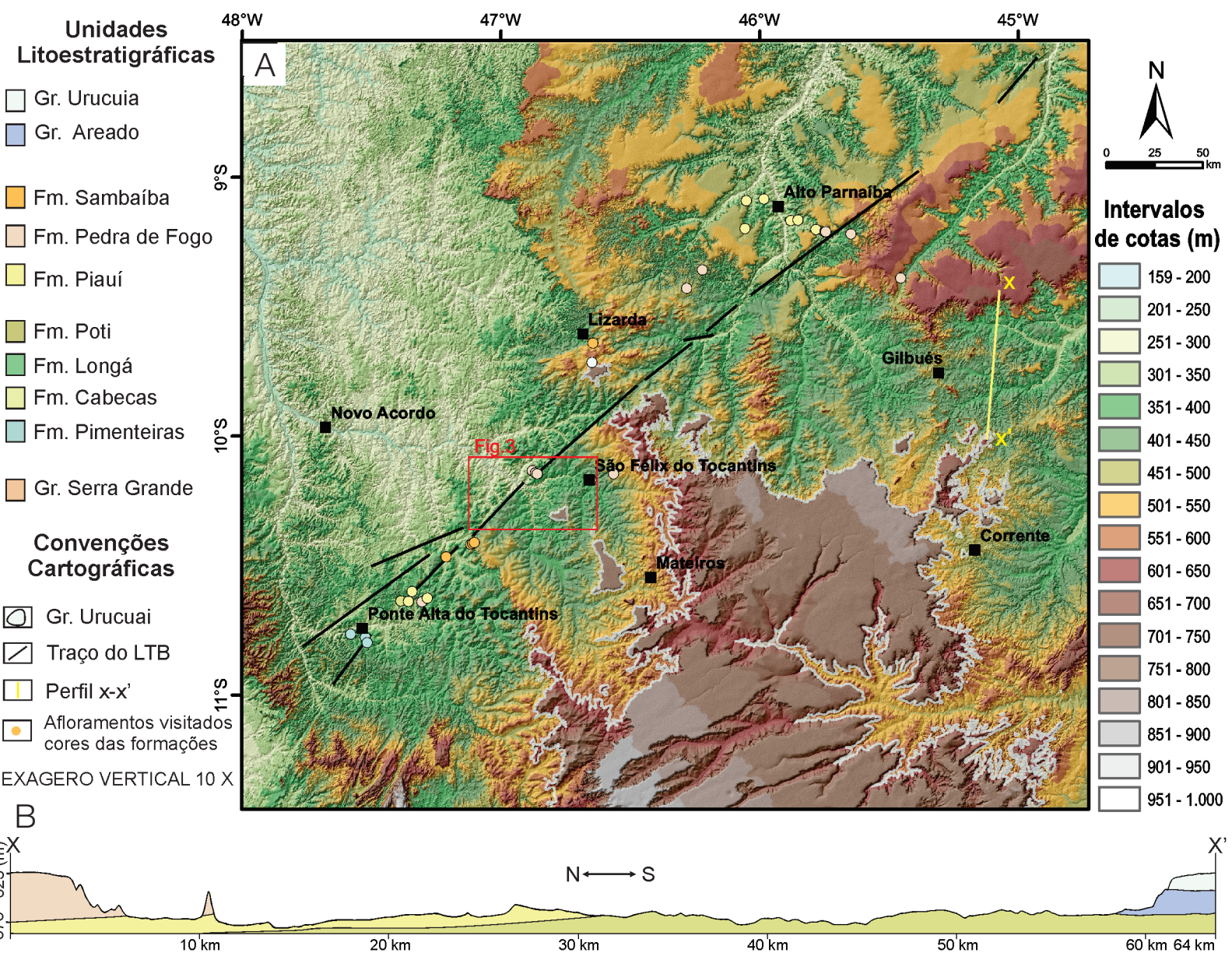

Figura 4. (A) Mapa altimétrico da região sul da BPar, com destaque para o trend do Lineamento Transbrasiliano (traço preto) e a nova configuração do Grupo Urucuia (contorno branco) proposta neste trabalho. (B) Perfil geológico N-S na região entre Gilbués e Corrente (ver indicação do perfil X-X' no mapa geológico - Figura 6). 
os platôs mais elevados da região ( $>600 \mathrm{~m}$ ), tendo nas encostas (ou platôs mais baixos que $450 \mathrm{~m}$ ) rochas da Formação Sambaíba. Escavada por vales e compondo uma extensa planície ao oeste de Mateiros (TO), parecem dominar os litotipos característicos da Formação Pedra de Fogo. Foi então necessário efetuar ajustes cartográficos nos mapas geológicos, nos quais houve diminuição da área aflorante do Grupo Urucuia e consequente aumento das áreas ocupadas pelos litotipos das Formações Pedra de Fogo (com seus litotipos característicos, incluindo estromatólitos silicificados) e Sambaíba. Desse modo, não foi comprovada a reativação do LTB nessa área de estudo, impressa em unidades cretáceas (ver Figura 4A).

$\mathrm{Na}$ região entre Corrente e Gilbués (PI), um mapa da CPRM (Folha SC. 23/Curimatá 1:250.000 - Arcanjo e Braz Filho, 1999) efetuou uma mudança também significativa, cartografando uma área aflorante da Formação Motuca, representada principalmente por rochas pelíticas, até então não caracterizada nesse setor da bacia. Pelo desconhecimento de dados biocronoestratigráficos que justifiquem a proposta nessa área de ocorrência, foi mantida a interpretação prévia (Vasconcelos et al., 2004) como rochas do Grupo Areado. Para confrontar as informações foi confeccionado um perfil geológico (Figura 4B), a fim de melhor caracterizar a região.

No perfil geológico $X-X$ ' (Figura 4B) observa-se que a cota da base do Grupo Areado (mais novo), ao sul, é apenas um pouco superior àquela da Formação Pedra de Fogo, ao norte, sendo que o Grupo Urucuia também exibe cota semelhante à da Formação Pedra de Fogo. Tais relações sugerem interpretações alternativas e/ou combinadas:

1. uma expressiva discordância erosional na base do Grupo Areado seria justificada pelo seu contato com a Formação Poti, imediatamente subjacente. Na porção norte no perfil, as Formações Piauí e Pedra de Fogo teriam sido removidas pela erosão, na borda da Bacia do Espigão Mestre, ou sendo esta borda um alto estrutural durante a deposição do Grupo Balsas (também deve ser notada a ausência da Formação Motuca, nessa região);

2. falhas com soerguimento relativo do bloco ao norte no corte (falhas normais correspondendo aos lineamentos ENE ?), entre outras possibilidades.

Ao sul da cidade de Lizarda (TO) foi descrito um afloramento que se mostrou importante para as relações cronoestratigráficas da região. Como uma franja acompanhando uma primeira escarpa sustentada pelos arenitos eólicos da Formação Sambaíba, foram observados arenitos e conglomerados de sistemas fluviais contendo abundantes fragmentos de rochas subvulcânicas básicas, sotopostas. Estas últimas constituem soleiras rasas (eventualmente também derrames) da Suíte Mosquito, as quais intrudem a Formação Sambaíba (Figuras 5Ae 5B). Com base nesses clastos, na semelhança dos litotipos e na sua petrografia microscópica, essas rochas sedimentares foram correlacionadas à Formação Corda, até então não reconhecida nessa porção sul da BPar.
Ainda foi considerada a hipótese de uma correlação dessa ocorrência com os sedimentos interderrames da Suíte Mosquito, descritos mais ao norte na região centro-oeste da bacia (Ballen, 2012; Moura, 2017). Todavia, nesse caso, essas rochas sedimentares não apresentam as feições microscópicas dos sedimentos interderrames, justificando a hipótese de sua correlação com a Formação Corda. O contato basal desses arenitos parece caracterizar uma importante discordância erosional (Figuras 5C e 5D). Em termos cartográficos, essa ocorrência ao sul de Lizarda foi inferida em mapa (Figura 6A), independentemente da extensa cobertura neógena presente na região (a qual também foi representada na cartografia; Figuras 6B e 6C). Desse modo, é possível que essa unidade ocorra em outras localidades na região, em cotas elevadas, mas sotoposta ao Grupo Urucuia. Finalmente, como citado, os fotolineamentos de direção ENE-WSW, na região ao sul de Lizarda (TO), afetam e/ou controlam os litotipos da Formação Sambaíba e as rochas subvulcânicas da Suíte Mosquito; com esta revisão cartográfica, verifica-se que essas estruturas também afetam a Formação Corda.

\section{Expressão das macroestruturas em subsuperfície}

A linha sísmica 0240-0316 (obtida do acervo do BDEP/ANP pelo Projeto Bacia do Parnaíba) tem $180 \mathrm{~km}$ de extensão, com orientação WNW-ESE, estando localizada na porção centro-oeste da área de estudo. Na seção foi possível definir seis horizontes sísmicos que, em comparação aos mapeamentos sísmicos com controle de poços, mais ao norte, foram correlacionados aos topos de algumas unidades litoestratigráficas que ocorrem na BPar. Alguns desses marcos correspondem a discordâncias, caso do topo da Formação Poti, que marca o limite das Sequências Mesodevoniana-Eocarbonífera e NeocarboníferaEotriássica. É facilmente identificado o topo do embasamento Pré-Cambriano, representando importante não conformidade. Também são identificados corpos magmáticos pertencentes à Suíte Mosquito. A Figura 7 mostra o resultado das interpretações realizadas ao longo da linha sísmica, em que é possível observar três compartimentos estruturais que serão descritos a seguir.

De forma geral, a seção apresenta refletores com baixa amplitude, camadas de mergulho suave para ESE e paralelas com grande continuidade lateral. Observa-se diminuição das espessuras no sentido WNW (especialmente a partir do topo da Formação Pimenteiras), refletindo a proximidade da borda oeste da BPar. Os estratos são afetados por falhas de alto ângulo com componentes de rejeito normal, mas também ocorrem falhas subverticais ramificadas, com componentes de rejeito normal ou inverso, interpretadas como estruturas-em-flor (rejeito direcional predominante). Com base nos mapas e em dados de superfície, interpreta-se que essas falhas apresentam direções principais NNW a NE, afetando desde o embasamento até o topo da Formação Pedra de Fogo, em alguns casos alcançando a Formação Sambaíba. 
As porções ocidental e central da seção apresentam, em sua maior parte, falhas normais de alto ângulo, que definem grábens estreitos e pouco profundos; os traços das falhas são observados até o topo das Formações Pimenteiras e Longá. Em superfície, essas estruturas apresentam direções N-S variando a NNW; e elas podem corresponder a juntas T e/ou fraturas híbridas, conforme discutido adiante. Além disso, são observadas estruturas com componente de rejeito inverso que afetam o horizonte correspondente ao topo do embasamento da BPar, bem como o topo das Formações Tianguá ou Pimenteiras.

Na porção mais ao leste da seção os estratos são fortemente afetados por um conjunto de estruturas em uma faixa com largura da ordem de $20 \mathrm{~km}$ que coincide com o traço principal do LTB. As feições incluem falhas com componente normal subverticalizadas e estruturas-em-flor e dobras associadas.
Observa-se o seu enraizamento no embasamento, mas, nesse setor, a visualização dos horizontes sísmicos fica prejudicada. Nessa região, as falhas em superfície apresentam direção NE-SW a ENE, podendo representar falhas de rejeito direcional e fraturas associadas, ou falhas com componentes normais. É característica dessa porção leste a ocorrência de refletores de alta magnitude, interpretados como soleiras básicas relacionadas ao Magmatismo Mosquito, como indicado pelos dados de campo.

\section{Evolução estrutural da borda sul da Bacia do Parnaíba}

Com base na assinatura cinemática e nos marcadores cronoestratigráficos associados, foram caracterizados quatro eventos deformacionais $\left(\mathrm{D}_{\mathrm{n}}, \mathrm{D}_{\mathrm{n}+1}, \mathrm{D}_{\mathrm{n}+2} \mathrm{e} \mathrm{D}_{\mathrm{n}+3}\right)$ afetando os diversos litotipos presentes na área de estudo, com destaque para as reativações do LTB.
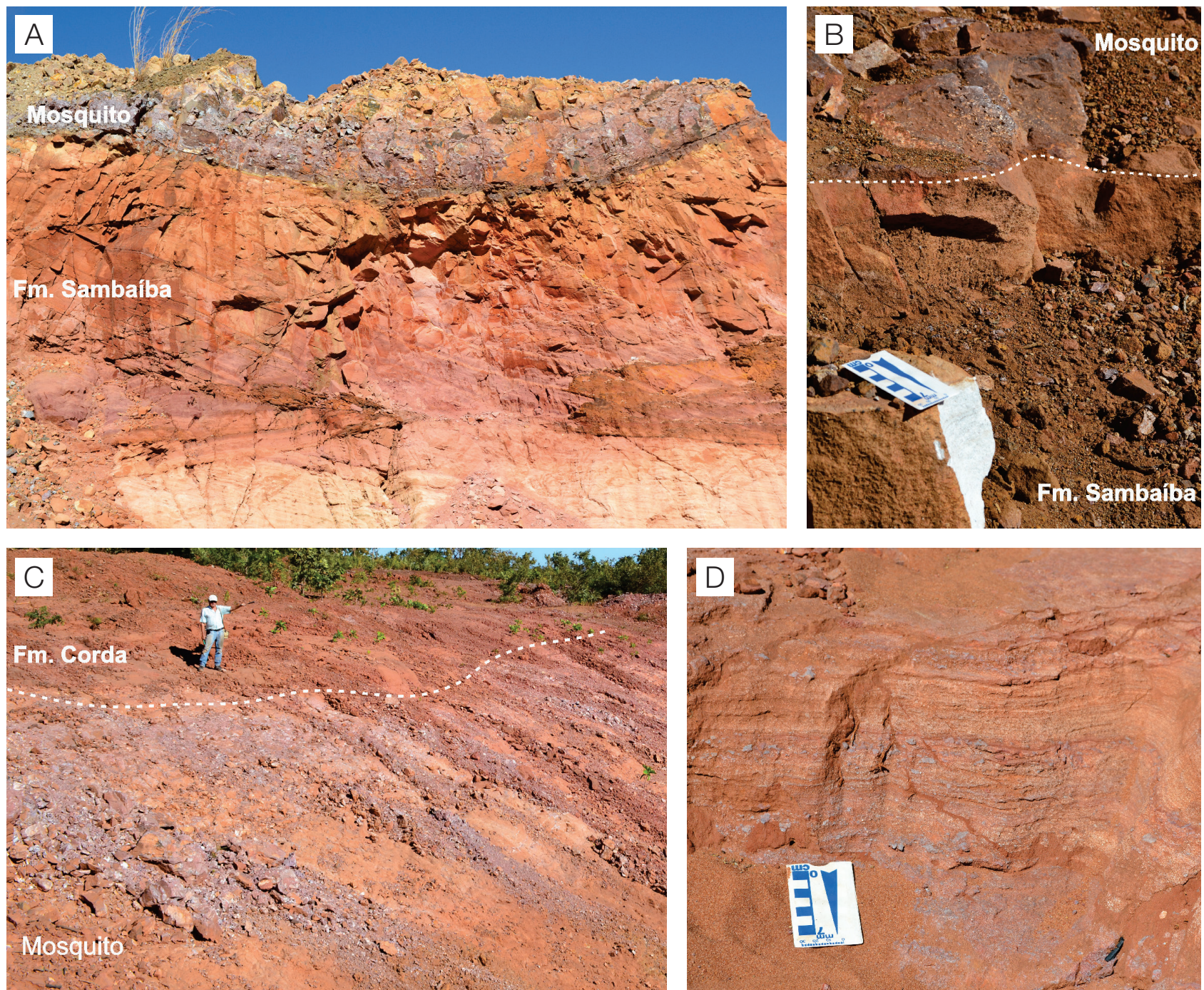

Figura 5. Relações estratigráficas do afloramento ao sul de Lizarda (TO). (A) Contato intrusivo entre soleira da Suíte Mosquito e arenitos da Formação. Sambaíba. (B) Detalhe do contato entre a soleira Mosquito e arenitos afetado por metamorfismo de contato. (C) Discordância erosional que marca a base da Formação Corda. (D) Detalhe da superfície irregular que separa os litotipos de rochas subvulcânicas da Formação Corda e detalhe dos clastos subvulcânicos na Formação Corda. 


\section{A fase deformacional $D_{n}$}

As estruturas frágeis da fase deformacional $\mathrm{D}_{\mathrm{n}}$ ocorrem em afloramentos ao longo de toda a expressão do LTB nessa região. Esta registra uma cinemática transcorrente sinistral, expressa principalmente por bandas de deformação e falhas (Figura 8A) com direção NE variando até NNE (falhas R, do modelo de Riedel) e, com menor frequência, ENE (falhas P). Combinadas a essas estruturas ainda ocorrem falhas normais ou normais oblíquas com orientação N-S a NNW (Figuras 8B e 8C).

A arquitetura de algumas bandas de deformação (Figura 8D), com o desenvolvimento de um fabric análogo a S/C de milonitos, mostra que a deformação ocorreu antes da completa litificação da rocha. Esse tipo de estrutura é classificado como hidroplástico (Araújo Netto et al., 2012).

As estruturas transcorrentes dextrais NW-SE representam falhas antitéticas do tipo R' (Figuras 8A e 8E) do modelo de
Riedel, em relação à estruturação maior (tomada como o traço do LTB, nas imagens); as falhas normais N-S são equivalentes a juntas $\mathrm{T}$ (Figura 8E), ao passo que as de direção NNW representam um conjunto de estruturas intermediárias entre R' e T. Na região da Serra da Catedral (um importante morro testemunho da Formação Sambaíba, em São Félix do Tocantins) foi observado um grande plano de falha de direção ENE, correlacionável a fraturas $\mathrm{P}$ (Figura 8F). A análise dos planos de falhas e respectivos slickenlines indica um campo de strain com eixo de distensão principal (X) com orientação E-W a ENE.

Na rodovia entre Alto Parnaíba (MA) e Gilbués (PI), estruturas-em-flor observadas na Formação Pedra de Fogo estão associadas a esse evento (Figura 9A). Elas exibem feições de espessamento de camadas (estruturas de crescimento) adjacentes à falha principal (Figura 9B), alternando estruturas em distensão (falhas e bandas de deformação com cinemática normal) ou contração (falhas inversas) nas suas bordas NW

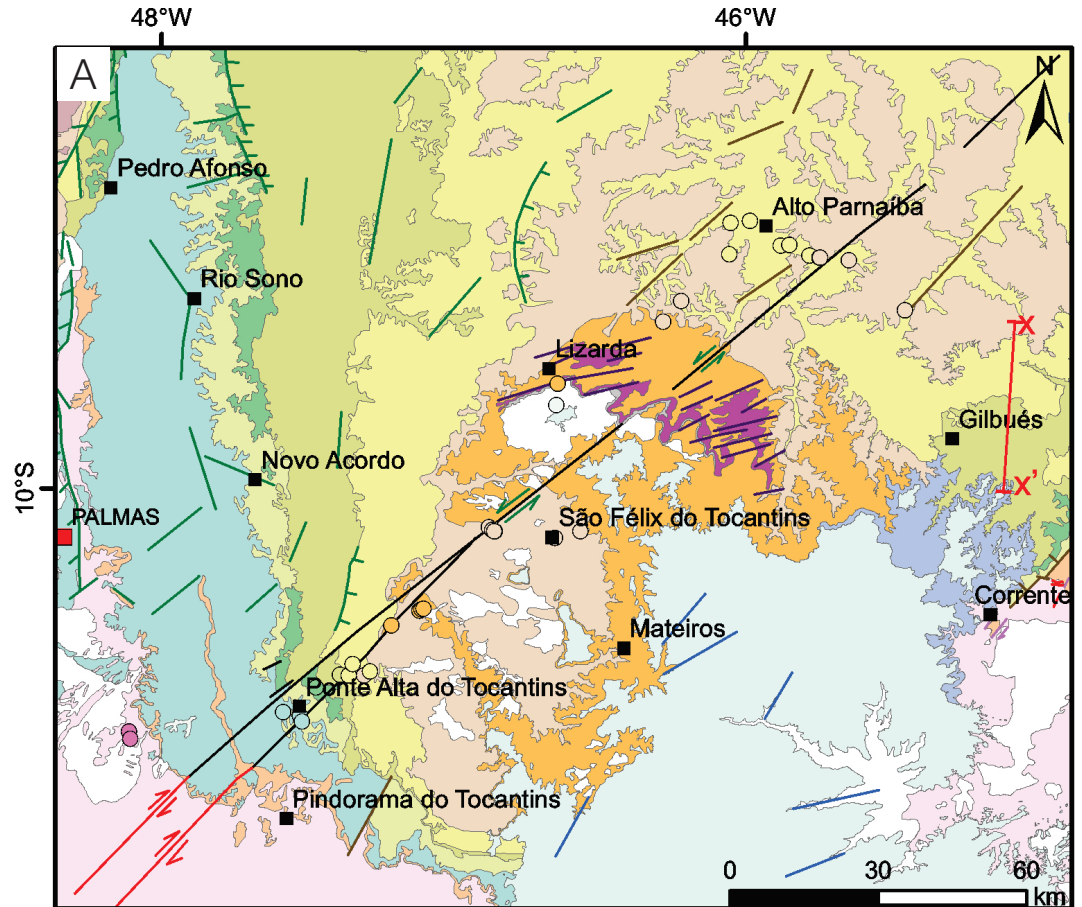

Unidades litoestratigráficas Paleógeno a Neógeno Depósitos aluviais e costeiros, paleodunas e Eo a Neocretaceo/Aptiano - Cenomaniano $\square$ Gr. Urucuia
$\square$ Gr. Areado Jurássico $\square$ Fm. Corda Suíte Magmática Mosquito, com intercalaçōes

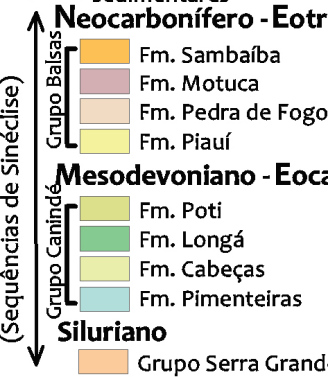
Pré-Cambriano - Cambriano $\square$ Embasamento cristalino indiviso Convenções cartográficas

- Sedes municipais - Capitais $\lambda$ Perfil geológico $\bigcirc$ Dados de

$\checkmark$ esquemático afloramentos

- Falhas de idade Ediacarana-Cambriana

_ Lineamento Transbrasiliano

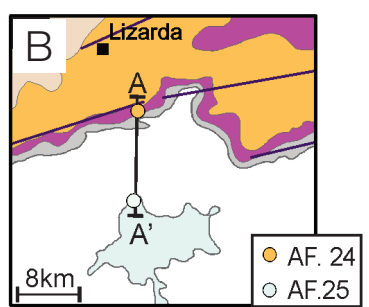

C $\mathrm{A}$

Lineamentos/falhas de idade Neopermiana-Eotriássica Lineamentos/falhas de idade Eojurrásica$$
\mathrm{N}
$$

N

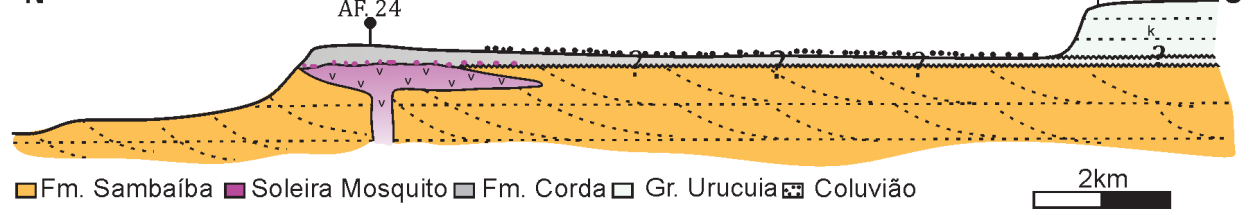

Figura 6. (A) Mapa geológico da área de estudo, com alterações na cartografia das unidades. (B) Detalhe no mapa geológico da região ao sul de Lizarda (TO). (C) Perfil síntese N-S das relações estratigráficas na região de Lizarda. 
e SE, respectivamente (Figuras 9C e 9D); esse arranjo estrutural é interpretado como a terminação NE de uma falha com essa direção (NE). As feições de crescimento das camadas e o caráter hidroplástico (Figura 8D) das estruturas evidenciam atividade tectônica sindeposicional a sinlitificação, o que confere a este evento deformacional uma idade neopermiana.

Este regime deformacional pode ser correlacionado às estruturas descritas por Souza (2016) na borda oeste da BPar, onde o autor caracteriza abertura oblíqua (componente sinistral) do Gráben de Araguaína, com direção geral N-S (distensão NE a ENE). Esse evento ocorreu em época equivalente, com base nas idades das formações afetadas e/ou controladas pela estruturação descrita (Formações Motuca e Pedra de Fogo; em parte Sambaíba, possivelmente como recorrências desse sistema de tensões) e na compatibilidade cinemática das estruturas, o que configura um campo de strain com amplitude regional. Estruturas preexistentes, incluindo anisotropias do embasamento Pré-Cambriano, foram reativadas ou influenciaram no estilo estrutural do evento aqui descrito.

\section{A fase deformacional $D_{n+1}$}

Este evento deformacional é caracterizado por estruturas distensionais, como juntas de distensão e falhas normais de direção ENE a E-W (Figura 10A). A partir dos planos de falhas e de bandas de deformação, com respectivas slickenlines, foi possível estabelecer um campo de strain com eixo de distensão (X) orientado NNW-SSE.

A hipótese de relacionar essas estruturas a uma reativação dextral do LTB (observada na borda leste da BPar) é julgada improvável, diante da aparente ausência (ou não observação) de indicadores cinemáticos dextrais na amostragem realizada

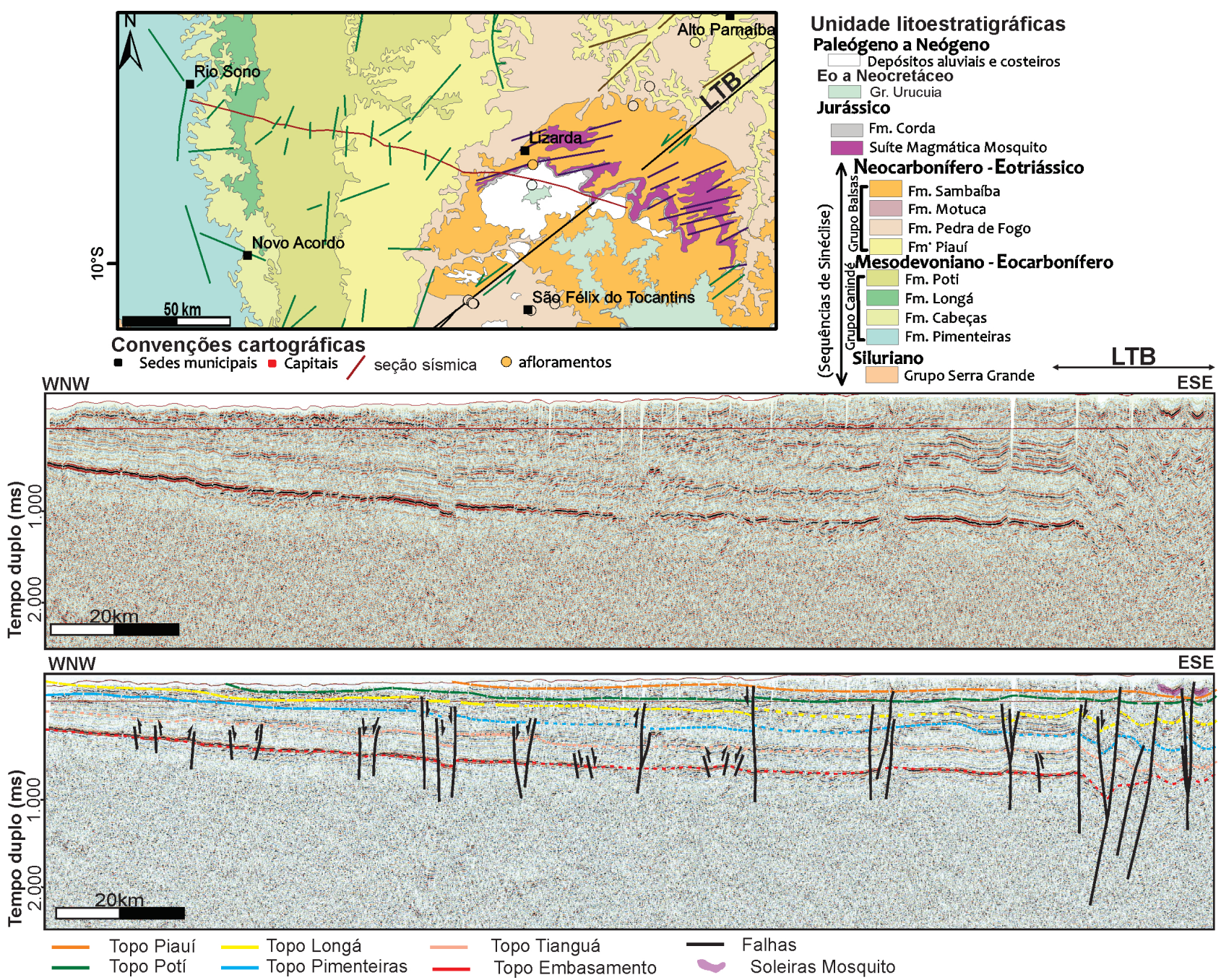

Figura 7. Seção sísmica sem interpretação e com interpretação de estruturas e topo das unidades, na região centrooeste da área de estudo. Observar que a estruturação do Lineamento Transbrasiliano oblitera as unidades/horizontes sísmicos no extremo leste da seção sísmica. 
nas falhas NE nessa porção sul da BPar. Em adição, a idade da reativação dextral observada no Grupo Serra Grande e na Formação Pimenteiras, nas bordas NE (Cacama et al., 2015) e SE (Lima, 2015) da bacia, é estimada no intervalo
Devoniano-Eocarbonífero. Finalmente, na sua área de ocorrência mais expressiva, na porção centro-oeste da BPar, onde é característica a sua impressão na Suíte Mosquito, as estruturas $\mathrm{D}_{\mathrm{n}+1}$ claramente truncam o trend $\mathrm{N}-\mathrm{S}$ do Gráben

\section{$\mathrm{Dn}$}
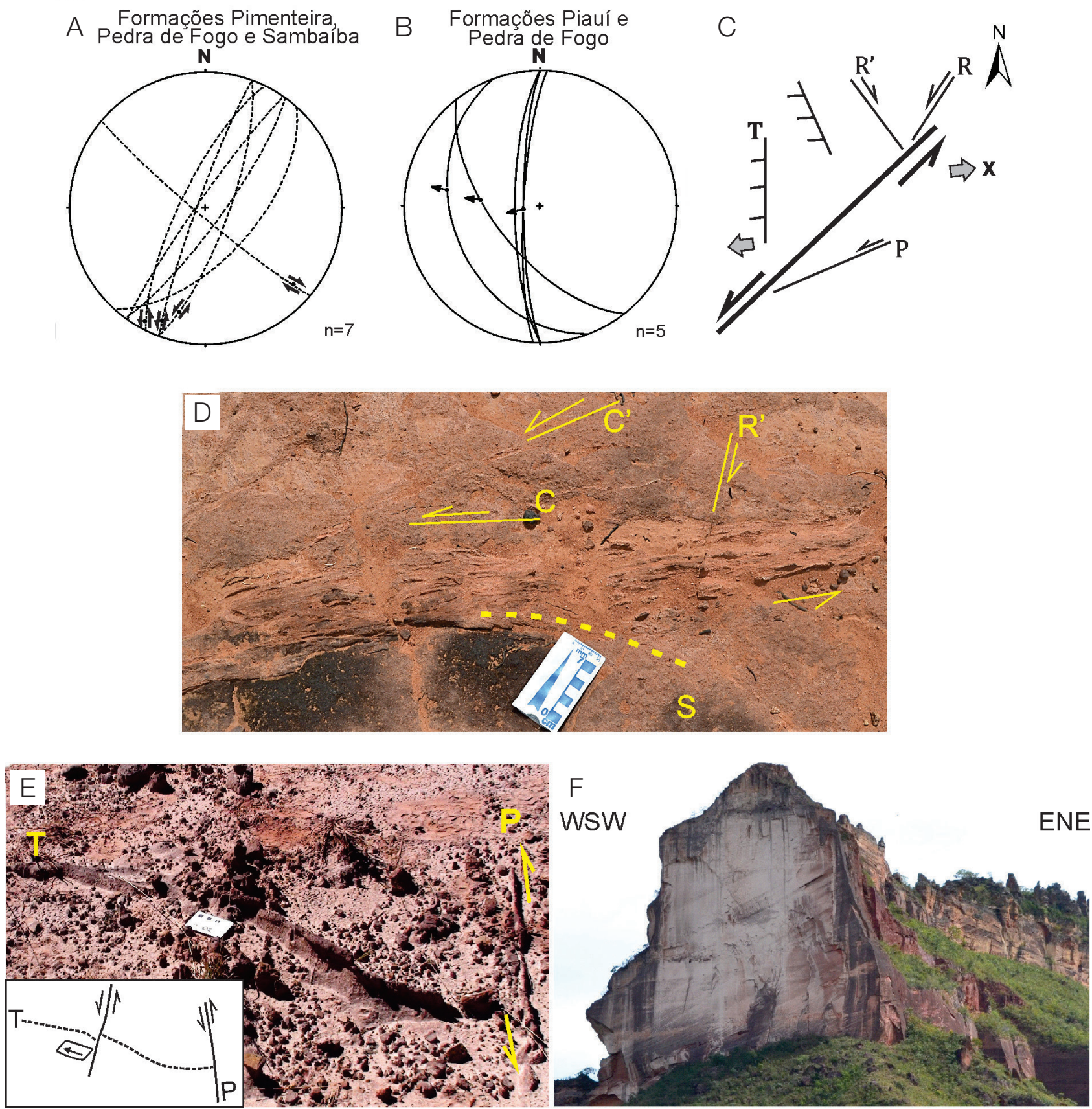

Figura 8. Projeções equi-área Schmidt-Lambert (hemisfério inferior) para estruturas relacionadas ao evento Dn. (A) Bandas de deformação e falhas transcorrentes sinistrais NE-SW e dextral NW-SE. (B) Falhas normais ou normais oblíquas (componente sinistral subordinado) com orientação N-S a NNW. (C) Modelo esquemático das falhas em mapa. (D) Detalhe da estrutura em D, mostrando critérios cinemáticos baseados em estruturas de segunda ordem (C' equivale a R no modelo de Riedel). (E) Banda de deformação com direção ENE. Juntas de distensão (T) sigmoidais associadas indicam transcorrência sinistral. (F) Plano de falha de direção ENE (equivalente a P) nos arenitos eólicos da Formação Sambaíba, na Serra da Catedral. Nas fotos, o cabo do martelo ou o marcador apontam para o norte. 
de Araguaína e não apresentam nenhuma relação de proximidade ou associação a macroestruturas de direção NE (Souza, 2016).

Este evento é expressivo na Formação Sambaíba, bem como nas unidades sotopostas (Figuras 10B e 10C), e controla/afeta os corpos diabásicos da Suíte Mosquito (além da Formação Corda, ao sul de Lizarda), conferindo uma idade eojurássica para o evento.

\section{A fase deformacional $D_{n+2}$}

$\mathrm{O}$ terceiro conjunto de estruturas, caracterizado por falhas normais ou normais oblíquas com direção NE-SW, mergulhando para NW ou SE (Figura 10D), foi observado principalmente nos litotipos do Grupo Serra Grande e das Fformações Itaim e Pimenteira (Figuras 10E e 10F). Em campo, os pontos onde foram observadas as estruturas relacionadas a esta fase posicionam-se ao longo de lineamentos de direção NE-SW seguindo o trend do LTB, sugerindo a reativação de estruturas mais antigas, agora em regime distensional. Esta fase corresponde a um campo de strain com eixo de distensão principal $(X)$ NW-SE e de encurtamento $(Z)$ vertical.

As estruturas deste evento são correlacionadas à distensão NW e estão associadas ao rifteamento eocretáceo na Província Borborema, com marcante assinatura na borda SE na BPar (Lima, 2015).
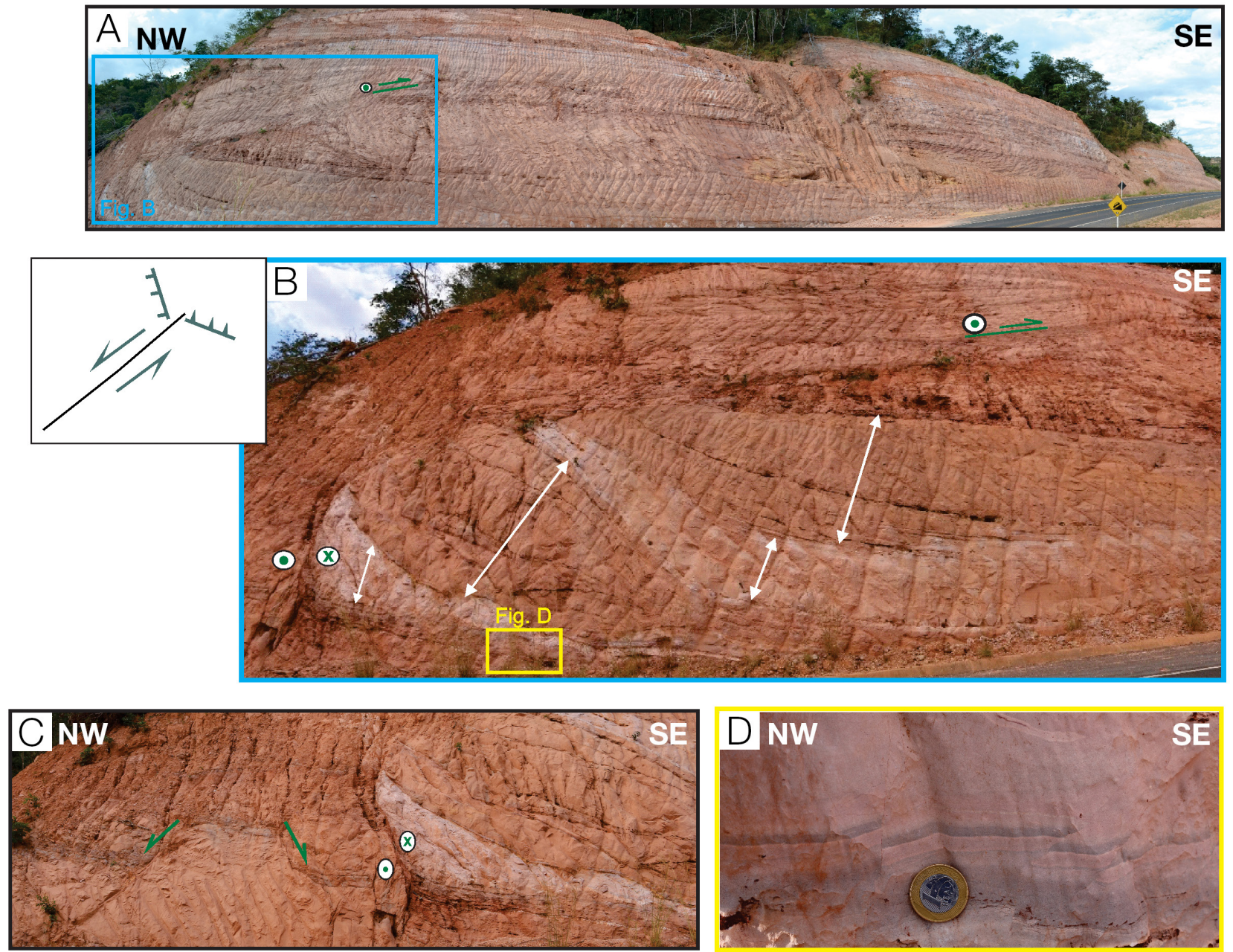

Figura 9. (A) Visão geral do afloramento próximo a cidade de Alto Parnaíba. Observar que as camadas na porção centro-sudeste do corte não se encontram afetadas por falhas e, deste modo, não evidenciam crescimento de seção. (B) Estrutura em flor com direção $\mathrm{NE}$, sinistral (ver modelo esquemático); observar o espessamento e truncamento de camadas e migração de depocentros (setas brancas). Mais acima no corte, observar estrutura de empurrão capeando as camadas espessadas, na terminação contracional da falha transcorrente (ver mapa modelo no inset). (C) Outra visão da estrutura em flor (porção esquerda da foto B), observando-se falhas e bandas de deformação normais na terminação distensional à esquerda na foto $B$ da transcorrência. (D) Pequenas falhas inversas sindeposicionais no bloco SE da transcorrência; localização da imagem no retângulo amarelo na figura B. 


\section{A fase deformacional $D_{n+3}$}

Finalmente, um quarto evento, de ocorrência restrita, é considerado a partir de minifalhas com direção NW-SE e rejeito (ou componente de mergulho) normal, observadas nos arenitos do Grupo Urucuia (de idade neocretácea), ao sul de Lizarda. Todavia, a população de dados (em especial, slickenlines) para este evento não é robusta o suficiente, mesmo para uma análise preliminar. Por outro lado, também foram observadas algumas falhas com direção NE-SW que podem refletir a reativação de estruturas na seção pré-cretácea da bacia.

\section{CONCLUSÕES}

A pesquisa desenvolvida até o momento permitiu reconhecer a ocorrência de diferentes populações de falhas, especialmente acompanhando a orientação NE-SW do LTB, na borda sul da BPar.

A cronologia das estruturas reconhecidas foi estabelecida com base nas unidades sedimentares, nas rochas básicas afetadas, na correlação com eventos geodinâmicos - abertura dos Oceanos Atlântico, Central e Sul - e em outros contextos orogênicos mais distais, influenciando na evolução estrutural da BPar.

Os trabalhos de campo e correlação com marcadores cronoestratigráficos requerida no estudo envolveram ajustes cartográficos em contatos/áreas aflorantes dos Grupos Urucuia e Areado (Bacia de Espigão-Mestre) e das Formações Pedra de Fogo e Sambaíba (Grupo Balsas) nessa borda da bacia. Esses ajustes foram executados por meio da interpretação de imagens (cenas do Google Earth e modelo digital de terreno utilizando cenas SRTM), com controle de dados de campo. Em adição, o reconhecimento de uma unidade siliciclástica com fragmentos das rochas básicas da Suíte Mosquito, correlacionada à Formação Corda, estabeleceu um novo marco cronoestratigráfico na região.

Quatro eventos deformacionais foram reconhecidos nessa região da BPar e caracterizados em termo de sua cinemática e provável idade.

A fase deformacional $D_{n}$ é considerada a mais antiga e mais expressiva na área de estudo, sendo caracterizada como uma reativação transcorrente sinistral nesse segmento SW do LTB. Além de sua impressão em unidades mais antigas, foram observadas estruturas-em-flor sindeposicionais na Formação Pedra de Fogo, combinadas com seu registro na Formação Sambaíba, o que confere uma idade no intervalo Neopermiano-Mesotriássico para este evento. Na borda oeste da BPar, que se conecta com o presente estudo na região ao sul/SE de Palmas (TO), as estruturas de grábens N-S com abertura oblíqua (componente sinistral) são compatíveis com a cinemática deste evento e com o intervalo cronológico aqui inferido (Souza, 2016). Nesse intervalo, a reativação transcorrente sinistral do LTB pode ser hipoteticamente atribuída a eventos tardios ou subsequentes a processos colisionais envolvendo o Gondwana ocidental e a Paleo-América do Norte. É interessante citar a observação de falhas transcorrentes sinistrais afetando diques graníticos com possível idade neocarbonífera, que ocorrem na zona de influência do LTB na região noroeste do Ceará (Amaral et al., 2017).

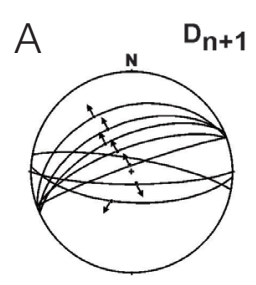

$n=8$

Grupo Serra Grande Pedra de Fogo e Sambaíba
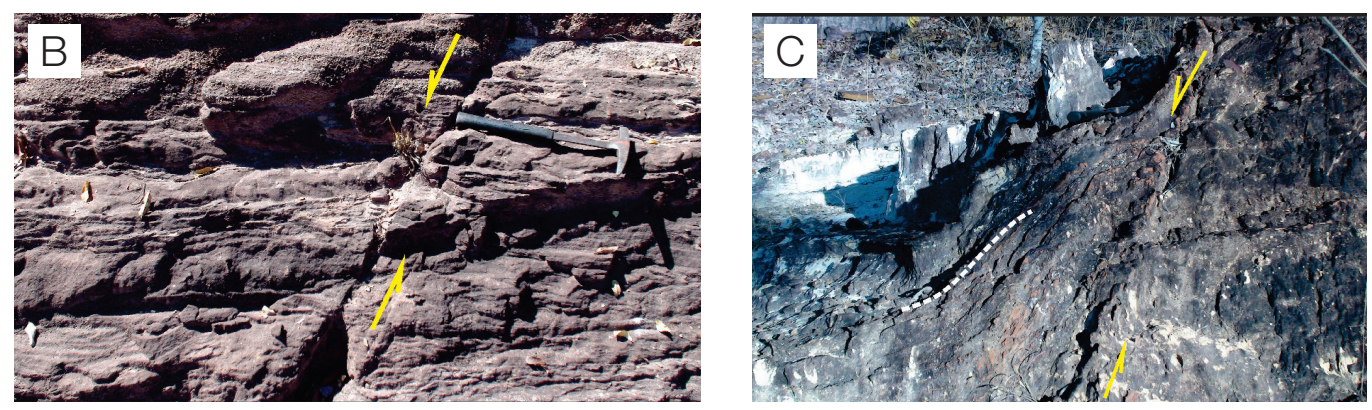

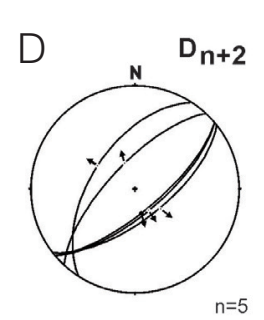

$n=5$

Grupo Serra Grande e Formação Itaim,Pimenteira
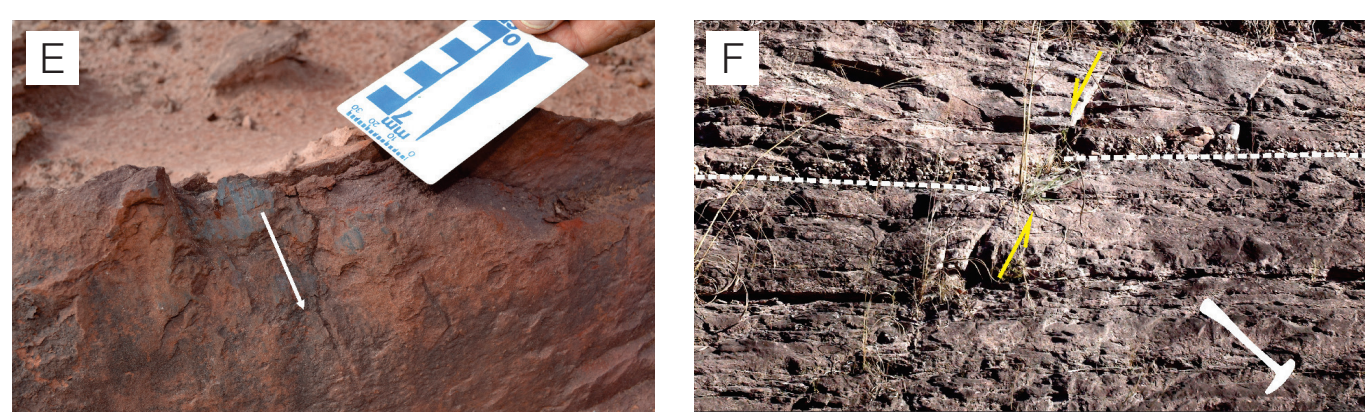

Figura 10. (A e D) Projeções equi-área Schmidt-Lambert (hemisfério inferior) para exemplos de estruturas relacionadas ao evento $D_{n+1}$ e $D_{n+2}$. (B) Deslocamento da camada de conglomerado da Formação Cabeças provocado pela falha de direção $E-W\left(D_{n+1}\right)$. (C) Dobra de propagação de falha (dobra de arrasto) na Formação Ipu $\left(D_{n+1}\right)$. (E) Detalhe da falha NESW e slickenlines da Formação Pimenteira $\left(D_{n+2}\right)$. (F) Deslocamento da camada de conglomerado da Formação Ipu $\left(D_{n+2}\right)$. 
O evento deformacional $\mathrm{D}_{\mathrm{n}+1}$ é de natureza distensional (distensão próxima de N-S) e de idade eojurássica, baseada na sua superposição e no controle do alojamento dos corpos básicos da Suíte Mosquito. Este evento magmático tem correlação com os processos associados à abertura do Oceano Atlântico Central (Zalán, 2004).

A fase deformacional $\mathrm{D}_{\mathrm{n}+2}$, caracterizada como uma distensão no eixo NW-SE que também reativou estruturas no trend NE do LTB, tem grande expressão na borda leste/sudeste da BPar (Lima, 2015) e pode ser correlacionada ao campo de strain que controlou o rifteamento no Nordeste ocidental (Província Borborema) durante o Eocretáceo (Matos, 1999; Lima, 2015).

Por fim, uma análise da fase $\mathrm{D}_{\mathrm{n}+3}$ estaria baseada em um registro localizado de estruturas em arenitos do Grupo Urucuia (Neocretáceo), ao sul de Lizarda (TO), as quais não puderam ser associadas aos eventos acima descritos. Preliminarmente, considerando que as falhas NW-SE com componente distensional deste evento são de idade neocretácea, a associação com a abertura da Margem Equatorial (distensão NW) ou com os eventos relacionados à Bacia do Espigão Mestre (porção norte da Bacia Sanfranciscana) são hipóteses a serem consideradas.

\section{AGRADECIMENTOS}

A pesquisa teve apoio da Chevron Brasil, que, em convênio com a UFRN, o PPGG e a Fundação Norte-Rio-Grandense de Pesquisa e Cultura (FUNPEC), financiou o projeto de pesquisa "Geologia e Sistemas Petrolíferos da Bacia Intracratônica do Parnaíba, Nordeste do Brasil". Os autores também agradecem a Dra. Valéria Centurión Córdoba, Pedro Moura e Gabriel Lima, pelas discussões visando ao aperfeiçoamento do texto; aos professores Rob Holcomb e Richard Allmendinger, pela cessão do programa de tratamentos de dados estruturais (faultKin). Agradecemos ainda a dois revisores anônimos da Revista Geologia USP. Série Científica, cujas observações muito contribuíram para a melhoria do presente texto.

\section{REFERÊNCIAS}

Almeida, F. F. M., Carneiro, C. D. R. (2004). Inundações marinhas fanerozóicas no Brasil e Recursos minerais associados. In: V. Mantesso Neto, A. Bartorelli, C. D. R. Carneiro, B. B. Brito Neves (Eds.), Geologia do continente sul-americano: evolução da obra de Fernando Flávio Marques de Almeida (43-48). São Paulo: Beca.

Amaral, W. S., Kraus, R. K., Dantas, E. L., Fuck, R. A., Pitombeira, J. P. A. (2017) Sinistral reactivation of the Transbrasiliano Lineament: Structural and geochronological evidences in the Cariré Granulite Zone, Borborema Province - NE Brazil. Journal of South American Earth Sciences, 79, 409-420. https://doi.org/10.1016/j.jsames.2017.08.022
Antunes, A. F., Silva, C. C. N., Jardim de Sá, E. F., Lira Lins, F. A. P., Córdoba, V. C., Sousa, D. C., Alves da Silva, F. C. (2015). Expressão Sísmica do Lineamento Transbrasiliano na Porção Sul-Sudoeste da Bacia do Parnaíba. XXVI Simpósio de Geologia do Nordeste, 24(1), 192. Natal: SBG - Núcleo NE.

Araújo Netto, J. M., Silva, F., Sá, E. (2012). Caracterização meso e microscópica de bandas de deformação em arenitos porosos: um exemplo nas tectonossequências Paleozoica, Pré- e Sin-rifte da Bacia do Araripe, Nordeste do Brasil. Geologia USP. Série Cientifica, 12(1), 83-98. http://dx.doi. org/10.5327/Z1519-874X2012000100007

Arcanjo, J. B. A., Braz Filho, P. A. (1999). Carta Geológica. Folhas SC.23-Z-A/Y-B/Z-B Curimatá/Corrente/XiqueXique. Brasil: CPRM.

Attoh, K., Brown, L. D. (2008). The neoproterozoic Trans-Saharan/Trans-Brasiliano shear zones: suggested Tibetan analogs. Eos Transactions, 89(23). Joint Assembly Supplement.

Ballen, A. R. (2012). Sucessões Sedimentares das Formações Mosquito e Corda: Exemplos de Sistemas Eólicos úmidos, Província do Parnaiba. Dissertação (Mestrado). São Paulo: Programa de Pós-Graduação em Geoquímica e Geotectônica, Instituto de Geociências - USP.

Cacama, M. S. J. B., Jardim de Sá, E. F., Alves da Silva, F. C., Lira Lins, F. A. P. (2015). Assinatura estrutural e geofísica da Porção Norte (fronteira Ceará-Piauí) do Lineamento Transbrasiliano: reativação na Bacia do Parnaíba. Geologia USP. Série Científica, 15(3-4), 67-81. http://dx.doi. org/10.11606/issn.2316-9095.v15i3-4p67-81

Castro, D. L., Bezerra, F. H., Fuck, R. A., Vidotti, R. M. (2016). Geophysical evidence of pre-sag rifting and postrifting fault reactivation in the Parnaíba basin, Brazil. Solid Earth, 7(2), 529-548. https://doi.org/10.5194/se-7-529-2016

Castro, D. L., Fuck, R. A., Phillips, J. D., Vidotti, R. M., Bezerra, F. H. R., Dantas, E. L. (2014). Crustal structure beneath the Paleozoic Parnaíba Basin revealed by airborne gravity and magnetic data, Brazil. Tectonophysics, 614, 128145. https://doi.org/10.1016/j.tecto.2013.12.009

Chamani, M. A. C. (2011). Tectônica Intraplaca e Deformação sinsedimentar induzida por abalos sísmicos: o Lineamento Transbrasiliano e Estruturas Relacionadas na Província Parnaiba, Brasil. Dissertação (Mestrado). São Paulo: Instituto de Geociências - USP. 
Chamani, M. A. C. (2015). Tectônica sinsedimentar no Siluro-Devoniano da Bacia do Parnaíba, Brasil: o papel de grandes estruturas do embasamento na origem e evolução de bacias intracratônicas. Tese (Doutorado). São Paulo: Instituto de Geociências - USP.

Cordani, U. G., Teixeira, W., D’Agrella-Filho, M. S., Trindade, R. I. (2009). The position of the Amazonian Craton in supercontinents. Gondwana Research, 15, 396407. https://doi.org/10.1016/j.gr.2008.12.005

Cordani, U. G., Pimentel, M. M., Araújo, C. E. G., Fuck, R. A. (2013). The significance of the Transbrasiliano-Kandi tectonic corridor for the amalgamation of West Gondwana. Brazilian Journal of Geology, 43, 583-597.

Ganade de Araujo, C. E., Weinberg, R. F., Cordani, U. G. (2014). Extruding the Borborema Province (NE-Brazil): a two-stage Neoproterozoic collision process. Terra Nova, 26(2), 157-168. https://doi.org/10.1111/ter.12084

Góes, A. M. (1995). A Formação Poti (Carbonifero Inferior) da Bacia do Parnaíba. Tese (Doutorado). São Paulo: Instituto de Geociências - USP.

Góes, A. M. O., Feijó, F. J. (1994). Bacia do Parnaíba. Boletim de Geociencias da Petrobras, 8, 57-67.

Jardim de Sá, E. F., Antunes, A. F., Nascimento da Silva, C. C., Sousa, D. C., Lira Lins, F. A. P., Alves da Silva, F. C., Lima, F. G. G., Moreira, J. A. M., Nascimento, M. A. L., Carneiro, M. S., Córdoba, V. C., Souza, Z. S. (2015). Arcabouço e Evolução Tectônica da Bacia do Parnaíba. XXVI Simpósio de Geologia do Nordeste, v. 24, 3-5. Natal: SBG-NE.

Lima, T. P. C. (2015). Expressão Geofisica-Estrutural do Lineamento Transbrasiliano na Porção Central da Bacia do Parnaíba (Maranhão-Piaui). Dissertação (Mestrado). Natal: Centro de Ciências Exatas e da Terra - UFRN.

Matos, R. M. D. (1999). History of the northeast Brazilian rift system: kinematic implications for the break-up between Brazil and West Africa. In: N. R. Cameron, R. H. Bate, V. S. Clure (Eds.), The oil and gas habitats of the South Atlantic. Geological Society. Special Publication, 153, 55-73.

Morais Neto, J. M. (2013). Expressão sísmica das reativações tectônicas do Lineamento Transbrasiliano na bacia do Parnaíba. VIII International Symposium on Tectonics, Extended Abstract. Chapada dos Guimarães: SBG - Núcleo Centro-Oeste.
Moura, P. R. S. (2017). Condicionamento Estrutural do Magmatismo Jurássico na porção centro-oeste da Bacia do Parnaiba. Relatório (Graduação). Natal: Universidade Federal do Rio Grande do Norte.

Nunes, K. C. (1993). Interpretação integrada da Bacia do Parnaíba com ênfase nos dados aeromagnéticos. III Congresso Internacional da Sociedade Brasileira de Geofísica, 152157. Rio de Janeiro: SBGf.

Oliveira, D. C., Mohriak, W. U. (2003). Jaibaras through: na important element in the early tectonic evolution of the Parnaíba interior sag basin, Northern Brazil. Marine and Petroleum Geology, 20, 351-383. https://doi.org/10.1016/S0264-8172(03)00044-8

Schobbenhaus, C. (Coord.). (1975). Carta Geológica do Brasil ao Milionésimo - Folha Goiás (SD 22) (texto explicativo). Brasília: DNPM. 114p.

Schobbenhaus, C., Gonçalves, J. H., Santos, J. O. S., Abram, M. B., Leão Neto, R., Matos, G. M. M., Vidotti, R. M., Ramos, M. A. B. (2004). Carta Geológica do Brasil ao Milionésimo: Sistema de Informações Geográficas - SIG e 46 folhas na escala 1:1.000.000. Brasília: CPRM. CD-ROM.

Souza, K. S. (2016). Análise Estrutural do Sistema de Grabens do Rio Tocantins, Borda Oeste da Bacia do Parnaiba (Tocantins, Pará e Maranhão). Dissertação (Mestrado). Natal: Centro de Ciências Exatas e da Terra - UFRN.

Vasconcelos, A. M., Kosin, M., Souza, J. D., Valente, C. R., Neves, J. P., Heineck, C. A., Lacerda Filho, J. V., Teixeira, L. R., Borges, V. P., Bento, R. V., Guimarães, J. T., Neves, J. P., Oliveira, I. W. B., Gomes, I. P., Malouf, R. F., Carvalho, L. M., Abreu Filho, W. (2004). Folha SC.23 - Rio São Francisco. In: Schobbenhaus, C.; Gonçalves, J.H.; Schneider Santos, J.O.; Abram, M.B.; Leão Neto, R.; Matos, G.M.M.; Vidotti, R.M.; Ramos, M.A.B.; Jesus, J.D.A. Carta Geológica do Brasil ao Milionésimo, Sistema de Informação Geográficas. Programa Geologia do Brasil. Brasília: CPRM.

Vaz, P. T., Rezende, N. G. A. M., Wanderley Filho, J. R., Travassos, W.A. S. (2007). Bacia do Parnaíba. In: E. J. Milani, H. D. Rangel, G. V. Bueno, J. M. Stica, W. R. Winter, J. M. Caixeta, O. C. Pessoa Neto (Eds.), Bacias sedimentares brasileiras - cartas estratigráficas. Boletim de Geociências da Petrobras, 15, 253-263.

Zalán, P. V. (2004). A Evolução Fanerozóica das Bacias Sedimentares Brasileiras. In: V. Montesso Neto, A. Bartorelli, C. D. R. Carneiro, B. B. Brito-Neves. Geologia do Continente Sul Americano - evolução da obra de Fernando Flávio Marques de Almeida, p. 595-612. São Paulo: Becca. 